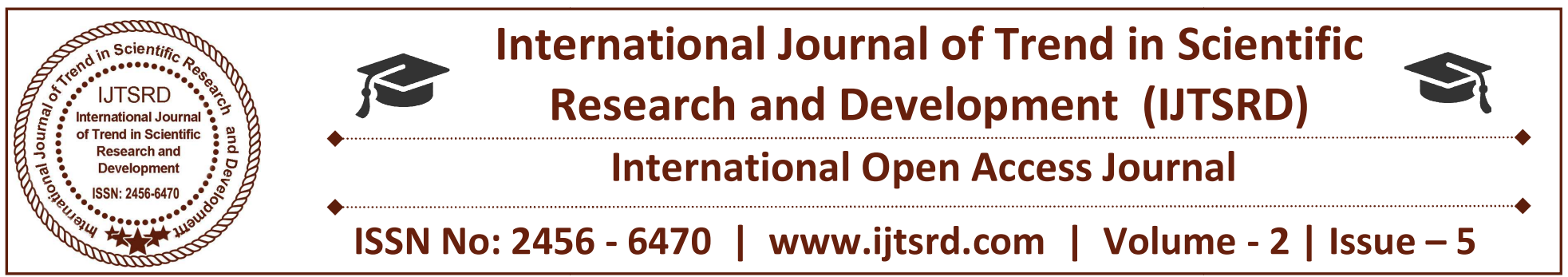

\title{
Corporate Leadership: A Study of the Mentoring Skills in Growing in the Corporate World
}

\author{
Dr. Satya Subrahmanyam \\ Professor, Head and Managing Partner \\ Vignan Institute of Technology and Management \\ Berhampur-, Golanthara, Brahmapur, Odisha, India
}

\section{ABSTRACT}

The intent of this research article is to understand the lived experience of those involved in mentoring relationships within a formal mentoring program in a corporate context. An attempt was made to look for rich detail about the nature of the relationship from the perspective of the mentor and mentee. To achieve a holistic perspective, the experience of corporate leaders was deliberately included. Findings suggested that the lack of a holistic approach to mentoring in the workplace may be creating counterproductive mentoring participant behaviours. TrValues misalignment may be creating cultural miscues that potentially misdirect mentoring program design and policies. Findings pointed to the need for increased integration of mentoring, leadership development, cultural transformation and corporate learning initiatives in order to better serve the aims of the corporate and increase the capacity of the workforce.

Keywords: Mentoring, Corporate Leadership, Selfefficacy, Global Perspective, Cultural Influence

\section{INTRODUCTION}

Mentoring has become a chameleon of opportunity (Holloway, 2005) within the modern workplace. With the corporate spending upwards of billions per year on formal training programs, which only account for five to nine percent of required employee learning (Tannenbaum, 1997), combined with the bulge of retirements looming from the baby-boom generation, corporate are searching for ways to protect their corporate knowledge, grow the knowledge base of new entrants into the workforce, increase capacity and lower costs. Mentoring seems to be right answer at the right time.
Much like a chameleon, mentoring programs and those involved in mentoring relationships are significantly influenced by environmental conditions (Kram, 1988; Zachary, 2005). In turn, mentoring can make a significant contribution to the transformation of corporate culture (Holloway \& Shoop, 2006). This reciprocal influence relationship between mentoring and the culture of the workplace has not received much attention and to some extent, the high-value business case for mentoring is hidden in plain sight. Certainly, the role of mentor as transfer agent of the culture (Wilson \& Elman, 1990) is not yet broadly acknowledged, while the corporate leader who still has responsibility for both cultural socialisation and career development of employees, if often excluded from mentoring program designs.

\section{STATEMENT OF THE PROBLEM}

Mentoring has been called a holistic and fluid concept that attends to professional, corporate and personal development (Stead, 2005), but mentoring in the workplace is often understood and practised as offline help (Clutterbuck \& Megginson, 1999) outside the mainstream of daily work. Even within the context of formal corporate mentoring programs, mentoring activities remain informal in the sense that there are few formal structures, little ongoing support for those engaged in mentoring relationships and typically, little accountability in terms of metrics or measures of individual outcomes from mentoring.

The focus of this research article was to consider the experience of those in mentoring relationships within a formal mentoring program in a specific corporate context. Whereas traditional informal mentoring relationships may involve only the mentor and mentee 
in the mentoring experience, formal mentoring programs within a corporate context suggest the involvement, to some extent, of the corporate leaders of the mentor and mentee, as illustrated in Figure 1:

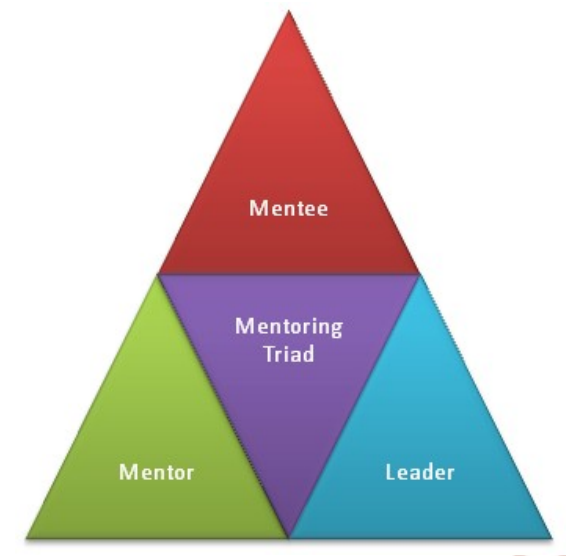

Cultural Influence

Figure 1: The Mentoring Triad in a Corporate Cultural Context

The triadic relationship between the mentor, the mentee and their respective corporate leader may be an important element in the research of mentoring relationships in the business domain. The goals they set within the context of their mentoring relationship often correspond to what they include in their personal development plans. The performance evaluation, the main instrument for employee performance appraisal, includes a section on leadership attributes where mentoring experiences are sometimes documented as evidence of the employee's pursuit of or demonstration of leadership.

\section{THE NEED FOR THE STUDY}

The primary purpose of this research article was to explore the experiences of participants in mentoring relationships within formal mentoring programs in a corporate setting. The mentoring relationship, when formalised through corporate mentoring program structures, extends the traditional dyadic form of mentor and mentee relationship to include corporate leaders. The purpose of this research article was to understand the dimensions of mentoring relationships in the workplace and to deliberately include the perspectives of the corporate leaders in the analysis. This triadic relationships and its influence on the mentoring experiences of participants have remained largely unexplored in the research literature.

Since the late 1970s, interest in mentoring in the workplace has steadily increased. When mentoring was first brought into the spotlight, it was predominantly engaged in by men in management for the purposes of succession planning and career development (Russell \& Adams, 1997). As women and minorities began entering the workforce in record numbers, the picture began to change.

Due to the globalisation, labour force becomes increasingly diverse and the multinational nature of corporate expands, research documenting the changing nature of mentoring relationships becomes more critical (Eby, 1997; Ragins, 1997). It will be important to understand the factors in these new corporates which facilitate or inhibit the formation and effectiveness of mentoring relationships (Russell \& Adams, 1997).

\section{RESEARCH QUESTIONS}

This research study researched the mentoring experiences of diversified corporate leaders who had experience as mentors, mentees and corporate leaders of mentors and/or mentees in a business domain, in the context of a formal corporate mentoring program.

1. What is all going on with regard to the relationships of corporate leaders who are mentors, mentees and leaders in the context of a formal corporate mentoring program?

2. What thare the dimensions of mentoring relationships that are grounded in the experience of the mentor, mentee and corporate leader?

\section{HYPOTHESIS}

$\mathrm{H}_{\mathrm{o}}$ : The necessity of mentoring skills is not growing in the corporate world in the era of post globalisation. $\mathrm{H}_{1}$ : The necessity of mentoring skills is growing in the corporate world in the era of post globalisation.

\section{REVIEW OF LITERATURE}

As the corporate world continues to move toward knowledge-based rather than industrial economy, successful organizations must evolve and adapt not only to the market but also to the changing wants and needs of their employees. Employees represent the most expensive and valuable asset. Retaining key employees and developing them into next generation of leaders is especially crucial now. Blass and Ferris (2007) argue that the current focus on technical competence is outdated and leader potential should be assessed by an individual's interpersonal savvy and influence ability.

The fluidity and informal nature of today's corporations have been discussed theoretically in terms of the changing nature of business (Semandar et 
al., 2006) and both employees and corporations must adapt to the informal structure to enhance employee satisfaction and performance in order to maximize shareholder wealth. As organizations become leaner and face increasing competition, fluidity in knowledge and skill become more valued in employees (Blass \& Ferris, 2007).

As corporations are acquired, merge or outsource employees find their jobs constantly changing, with new skill sets needed on a regular basis. Crossdepartmental teams form and dissolve based on specific projects and employees must navigate complex work situations in a dynamic environment. Having a strong belief in one's abilities or a sense of self - efficacy is argued to be important to individuals who find themselves in these changing roles and who face new co-workers and tasks regularly (Gist, 1987). It has been suggested that increasing organizational stressors, uncertainty about the future and increasing responsibility lead to an increased need for mentioning support (Mezias \& Scandura, 2005). Mentoring relationships are dynamic and constantly evolving. Kram (1983) developed a theory conceptualizing the overall phases of the mentoring relationship. Early theoretical conceptualizations of mentoring relationships focused on the career development and psychosocial support both members receive (Kram, 1983).

Scandura (1992) focused more on the role modelling dimension and supported its inclusion as a separate third dimension of mentoring. Further research and scale development (Castro, Scandura \& Williams, 2006) on mentoring has confirmed that it can be considered a three-factor construct, with role modelling encompassing mentor behaviour that can be observed and imitated by the protégé. Later research by Lankau \& Scandura (2002), showed a link between role modelling and skill development.

\section{FUNCTIONS OF A MENTOR}

Understanding the functions of a mentor will assist in providing a distinction between the role of mentor versus coaching and or managers. Mentoring provides a way for individuals to improve his or her skills in order to advance to the next level in which a person is attempting to achieve (Hicks \& McCracken, 2009). Comprehensive approach mentors may seek for their mentees may entail the emphasizing of leadership and skill building opportunities for both the mentor and the mentee (Hicks \& McCracken, 2009).
Clawson stated his contingency theory of mentoring, suggested a mentoring relationship as consisting of three contingency - type relationships (Horton, 1996). In the first contingency - type, protégés have a desire to learn from their mentors, merely for their own selfdevelopment purposes. The second type explains a sense of trustworthiness as associated with individuals who are mentors. Lastly, the mentor actively accepts the protégé and vice versa (Walker, 2008).

Wagner (2009) described the mentorship roles of the mentee and mentor are increasingly switching responsibilities as new hires are employed with organizations and have unique skill sets that tenured employees do not always possess. Building strategic leaders is an important aspect to the success of an organization because these leaders formulate the goals and strategies of the organization (Bass, 2007). According to Baddort (2009), trust is an essential element in a relationship - including in an organizational relationship between an individual and a corporation. Several essential traits of an effective manager, leader or mentor include - confidentiality, dependability, genuine, high moral and ethical standards, honesty, integrity and being professionally competent.

\section{INFORMAL VS FORMAL MENTORING}

The functions of a mentor vary while providing the ability to offer an opportunity to boost their protégés self - esteem (Kram, 1983). Self - esteem can be enhanced either formally or informally through various types of mentoring relationships. The basic distinction between informal and formal mentorships relies on how the relationship was formed (Karkoulian, Halawi \& McCarthy, 2008). Informal mentorships can exist with parents, teachers, friends and co-workers.

Lim (2008) stated that mentorships supplement parental support and are not intended to replace it. Informal mentorships can grow from informal events, relationships and interaction, which are not solely dependent upon a workplace context (Wallin \& Crippen, 2008). Formal mentorships are created when a mentor and mentee agree to a mutual work relationship to enhance career development by providing expectations, setting guidelines and conducting an orientation to assist trust acquisition (Chao, Walz \& Cardner, 1992). Formal mentorships can benefit both parties in terms of career development or personal development. Organisations 
have recognized the importance of mentorships by formalizing the process for career development management and leadership positions (Chao et al., 1992). An important aspect of mentoring is the willingness of participants to engage in the relationship (Hansman, 2003). Individuals must understand their roles in the mentoring relationship, which helps both parties to realize the benefits.

\section{SELF-EFFICACY}

The concept of self - efficacy is rooted in Albert Bandura's (2007) social cognitive theory. The initial step on the path to leadership is the individual's belief in his capacity to lead others or self - efficacy. Successful execution of a challenging goal is an especially potent type of mastery experience and contributes strongly to self - efficacy. Mastery experiences are the most important source of self efficacy. Social persuasion builds self - efficacy by virtue of the empowering nature of praise and encouragement from another person.

Self - efficacy for leadership is important because of the implications for businesses and individuals. Because people generally seek activities for which they have high self - efficacy (Pajares, 1994), being able to assess and enhance leadership self - efficacy is critical for building the next generation leaders. People with high self - efficacy believe themselves capable of a wider variety of and more prestigious careers (Bandura, 1994), thus individuals with a well developed a sense of self - efficacy are more likely to attempt leadership positions.

\section{MENTORING AND CORPORATE \\ LEADERSHIP}

Kram explained the goal of a mentor is primarily to develop mentees for career growth (Rabe \& Beehr, 2003). Career support and development from a mentor is more likely to provide a satisfied employee who is committed and less likely to depart from the corporation. Leaders should ensure the development is available for their employees by structuring the organization in accordance with preferences and needs that will assist in meeting the goals of the corporation.

According to Paglis and Green (2002) leadership exerts by setting a direction for the workgroup, building relationships with followers in order to gain their commitment to change goals and working with them to overcome obstacles to change. With increasing competitive pressures and strong impetus for innovation, corporate leaders must be willing to try new ideas, even with the risk of failure. Individuals with high self - efficacy are less likely to hold defeatist attitudes and tend to view setbacks as challenges and as Bandura (1994) points out, corporations are made stronger by a workforce that believes - individually and collectively, in its ability to successfully navigate challenges. Individuals with high leadership self - efficacy are also more likely to be rated by their peers and superiors as capable and confident (Chemers, Watson \& May 2000).

\section{METHODOLOGY}

There are two principal research paradigms that can be used in business research, namely - the positivistic and a phenomenological / interpretivism paradigm. According to Bryman and Bell (2007), positivism is an epistemological position that advocates the application of the methods of the natural sciences to the study of social reality and beyond. The role of positivism as stated by Anderson (2004) resides in searching for facts in terms of clarifying the relationship between variables before identifying a data collection pattern through statistical approaches as followed in quantitative research procedures. According to Collis and Hussey (2003), the positivistic approach concentrates on facts and the causes of social events, paying modest respect to the subjective state of the individual.

The quantitative research is built on a numerical measurement of specific characteristics related to a phenomenon. Quantitative approaches employ deductive logic, moving from the general to the specific. The tools used to carry out quantitative research tend to be surveys and questionnaires (Coombes, 2001). It is a very structured approach and is most often focused on objectivity, generalisability and reliability (Collis \& Hussey, 2003). The key advantage of the quantitative approach, therefore, is that it is based on fact and reliable data that enables researchers to generalize their findings to the population from which the sample has been drawn.

A non-experimental research design is an appropriate approach to determine if a specific treatment (Mentoring skills of a corporate leader) influences an outcome (corporate leadership skills and effectiveness of the corporate) using a sample that is not randomly assigned to a treatment or comparator group (Creswell, 2014). 
A questionnaire according to Collis and Hussey (2003) can be used to gather data when the issues which arise are likely to be confidential and sensitive and give respondents more time to consider their answers. The questionnaire survey, as defined by McDaniel and Gates (2002) is comprised of a set of questions designed to generate the evidence necessary to accomplish the objectives of the research study. It is a method of getting answers to the research questions based on designing specific questions to be answered by the research participants (Robson, 2002). Questionnaires as a survey method may be viewed as a comparatively simple and uncomplicated means of examining participants' attitudes, values, beliefs and motives. When the survey includes sensitive issues, a questionnaire affords a high level of confidentiality and anonymity (Robson, 2002).

The questionnaire consisted of five close-ended questions with an open-ended section at the end of the questionnaire for participants to add any further comments about their perception of the mentoring skills. The response scales took the form of the Likert Scale. The Likert scale is one of the most widely used response scales in research and is used to evaluate behaviour, attitude or another phenomenon on a continuum. Rating scales simplify and more easily quantify peoples' behaviours or attitudes (Leedy \& Ormrod, 2005). A neutral response option has not been given which might prove a bit disastrous if the majority of the respondents decide to choose this, thus posing a danger of not being able to conduct an optimal evaluation.
The sample size is a significant characteristic of any empirical study in which the goal is to make assumptions about a population based on a sample. Indeed, the sample size used in the study was determined based on the data collection figures and the need to obtain sufficient statistical power (Saunders et al., 2009). Saunders et al. added that the larger the sample size, lower the likely error in generalizing to the population.

The survey was distributed to a purposeful sample of 300 participants includes corporate leaders from a different spectrum, represents different areas of specialization and comprises different sectors. Statisticians contend that as a sample size increases, variability (i.e., effort variance) decreases and power increases. As power increases to detect a false null hypothesis, there is an increased risk of falsely rejecting a true null hypothesis.

\section{ANALYSIS}

The survey asked a series of questions in order to establish whether there is a relationship between mentoring skills of a corporate leader and the effectiveness of the corporate functioning. And the focus of the research and the survey is to find out whether the prominences of mentoring skills growing in the corporate world. This section provides a summary of the information that was collected through a questionnaire. The following tables and figures provide a snapshot of mentoring skills of a corporate leader.

Table 1: Listening to protégé

\begin{tabular}{|c|c|c|c|c|c|c|c|}
\hline \multirow{2}{*}{ Indicator } & \multicolumn{3}{|c|}{ Non-Agree } & \multicolumn{3}{c|}{ Agree } \\
\cline { 3 - 8 } & $\begin{array}{c}\text { Strongly } \\
\text { Disagree }\end{array}$ & $\begin{array}{c}\text { Dis- } \\
\text { Agree }\end{array}$ & Total & Agree & $\begin{array}{c}\text { Strongly } \\
\text { Agree }\end{array}$ & Total \\
\hline \multirow{2}{*}{1} & $\begin{array}{c}\text { In your opinion, a leader listens } \\
\text { alternatively to both words and } \\
\text { feelings of his / her protégé. }\end{array}$ & $\begin{array}{c}51 \\
(17)\end{array}$ & $\begin{array}{c}75 \\
(25)\end{array}$ & $\begin{array}{c}126 \\
(42)\end{array}$ & $\begin{array}{c}63 \\
(21)\end{array}$ & $\begin{array}{c}111 \\
(37)\end{array}$ & $\begin{array}{c}174 \\
(58)\end{array}$ \\
\hline
\end{tabular}

The survey respondents were asked whether a corporate leader should listen alternatively to both words and feelings of his/her protégé. As good as $58 \%$ responded positively that a corporate leader should be an active listener to both words and feelings of his/her protégé. 
Figure 2: Listening to protégé

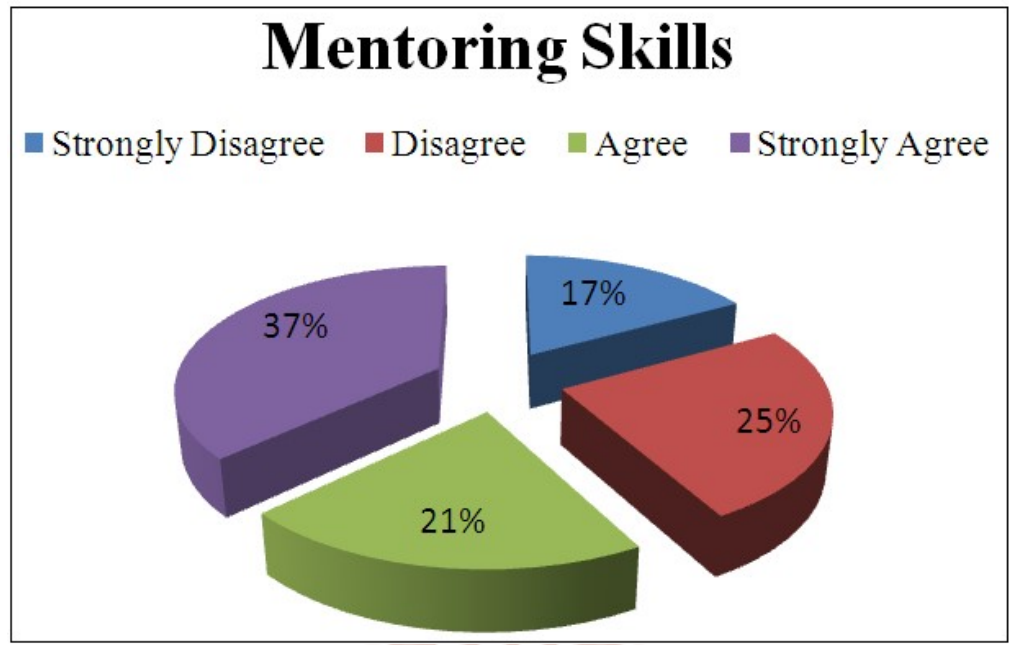

Table 2: Confronting Negative Attitudes

\begin{tabular}{|c|c|c|c|c|c|c|c|}
\hline \multirow{2}{*}{ Indicator } & \multicolumn{3}{|c|}{ Non-Agree } & \multicolumn{3}{c|}{ Agree } \\
\cline { 3 - 8 } & $\begin{array}{c}\text { Strongly } \\
\text { Disagree }\end{array}$ & $\begin{array}{c}\text { Dis- } \\
\text { Agree }\end{array}$ & Total & Agree & $\begin{array}{c}\text { Strongly } \\
\text { Agree }\end{array}$ & Total \\
\hline \multirow{2}{*}{2} & $\begin{array}{c}\text { In your opinion, a leader feels } \\
\text { comfortable confronting negative } \\
\text { attitudes or behaviours. }\end{array}$ & $\begin{array}{c}45 \\
(15)\end{array}$ & $\begin{array}{c}180 \\
(30)\end{array}$ & $\begin{array}{c}135 \\
(45)\end{array}$ & $\begin{array}{c}81 \\
(27)\end{array}$ & $\begin{array}{c}84 \\
(28)\end{array}$ & $\begin{array}{c}165 \\
(55)\end{array}$ \\
\hline
\end{tabular}

The survey respondents were asked whether a corporate leader should feel comfortable confronting negative attitudes or behaviours of employees. Around $55 \%$ of the respondents agreed that a corporate leader should feel comfortable in confronting negative attitudes or behaviours of his employees.

Figure 3: Confronting Negative Attitudes

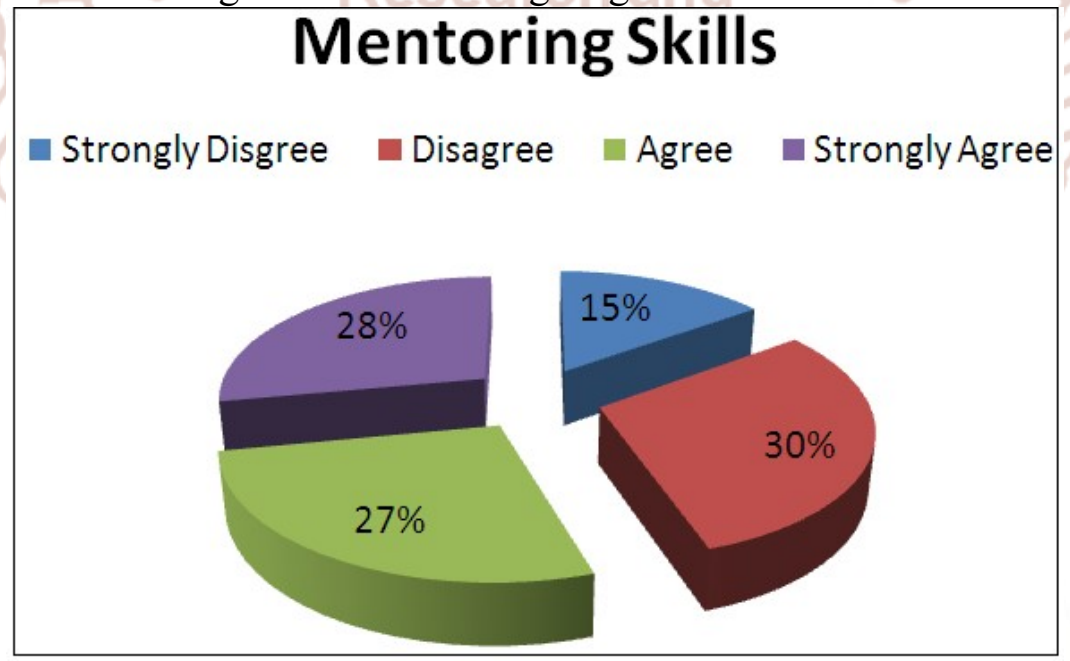

Table 3: Granting Second Chance

\begin{tabular}{|c|c|c|c|c|c|c|c|}
\hline \multirow{2}{*}{ Indicator } & \multicolumn{3}{|c|}{ Non-Agree } & \multicolumn{3}{|c|}{ Agree } \\
\cline { 3 - 7 } & $\begin{array}{c}\text { Strongly } \\
\text { Disagree }\end{array}$ & $\begin{array}{c}\text { Dis- } \\
\text { Agree }\end{array}$ & Total & Agree & $\begin{array}{c}\text { Strongly } \\
\text { Agree }\end{array}$ & Total \\
\hline \multirow{2}{*}{3} & $\begin{array}{c}\text { In your opinion, a leader gives } \\
\text { people another chance when they } \\
\text { fail. }\end{array}$ & $\begin{array}{c}66 \\
(22)\end{array}$ & $\begin{array}{c}96 \\
(32)\end{array}$ & $\begin{array}{c}162 \\
(54)\end{array}$ & $\begin{array}{c}72 \\
(24)\end{array}$ & $\begin{array}{c}66 \\
(22)\end{array}$ & $\begin{array}{c}138 \\
(46)\end{array}$ \\
\hline
\end{tabular}

The survey respondents were asked whether a corporate leader consider providing a second chance to whose fail in their responsibilities. Surprisingly, $54 \%$ of the respondents disagreed to provide a second chance to those who fail in discharging their responsibilities as planned. 
Figure 4: Granting Second Chance

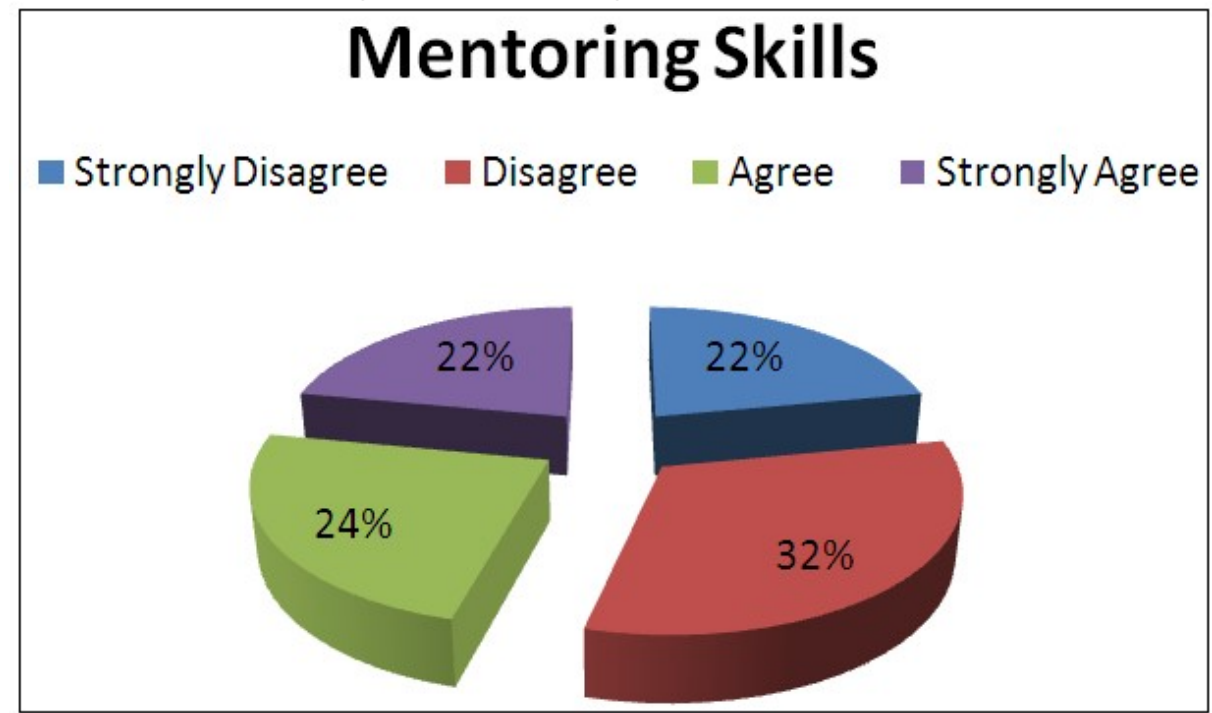

Table 4: Quoting self-examples

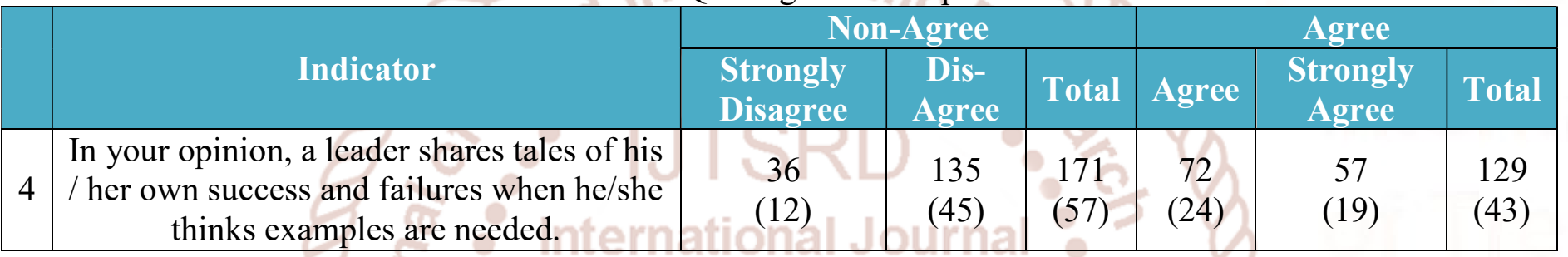

The survey respondents were asked whether a corporate leader shares tales of his/her own success and failures when the situation requires so. Again as high as $57 \%$ of respondents negatively responded that they did not like the idea of sharing their success and failures with their employees even those examples are warranted by the situation.

Figure 5: Quoting self-examples

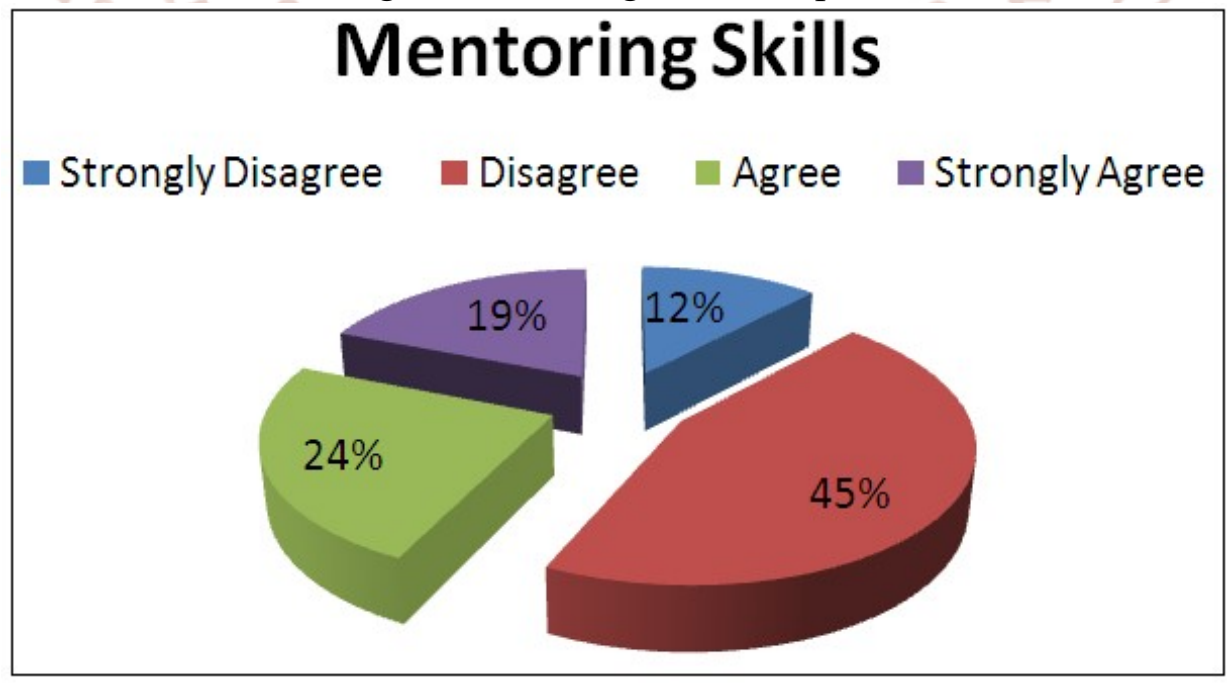

Table 5: Constant Touch

\begin{tabular}{|c|c|c|c|c|c|c|c|}
\hline \multirow{2}{*}{ Indicator } & \multicolumn{3}{|c|}{ Non-Agree } & \multicolumn{3}{c|}{ Agree } \\
\cline { 3 - 8 } & $\begin{array}{c}\text { Strongly } \\
\text { Disagree }\end{array}$ & $\begin{array}{c}\text { Dis- } \\
\text { Agree }\end{array}$ & Total & Agree & $\begin{array}{c}\text { Strongly } \\
\text { Agree }\end{array}$ & Total \\
\hline 5 & $\begin{array}{c}\text { In your opinion, a leader tries to be } \\
\text { available for immediate contact whenever } \\
\text { his / her protégé needs him/her. }\end{array}$ & $\begin{array}{c}66 \\
(22)\end{array}$ & $\begin{array}{c}78 \\
(26)\end{array}$ & $\begin{array}{c}144 \\
(48)\end{array}$ & $\begin{array}{c}69 \\
(23)\end{array}$ & $\begin{array}{c}87 \\
(29)\end{array}$ & $\begin{array}{c}156 \\
(52)\end{array}$ \\
\hline
\end{tabular}


The survey respondents were asked whether a corporate leader should available for subordinates to contact instantaneously. A majority $52 \%$ of respondents agreed positively that a corporate leader should make him/her to be available for his staff instantaneously.

Figure 6: Constant Touch

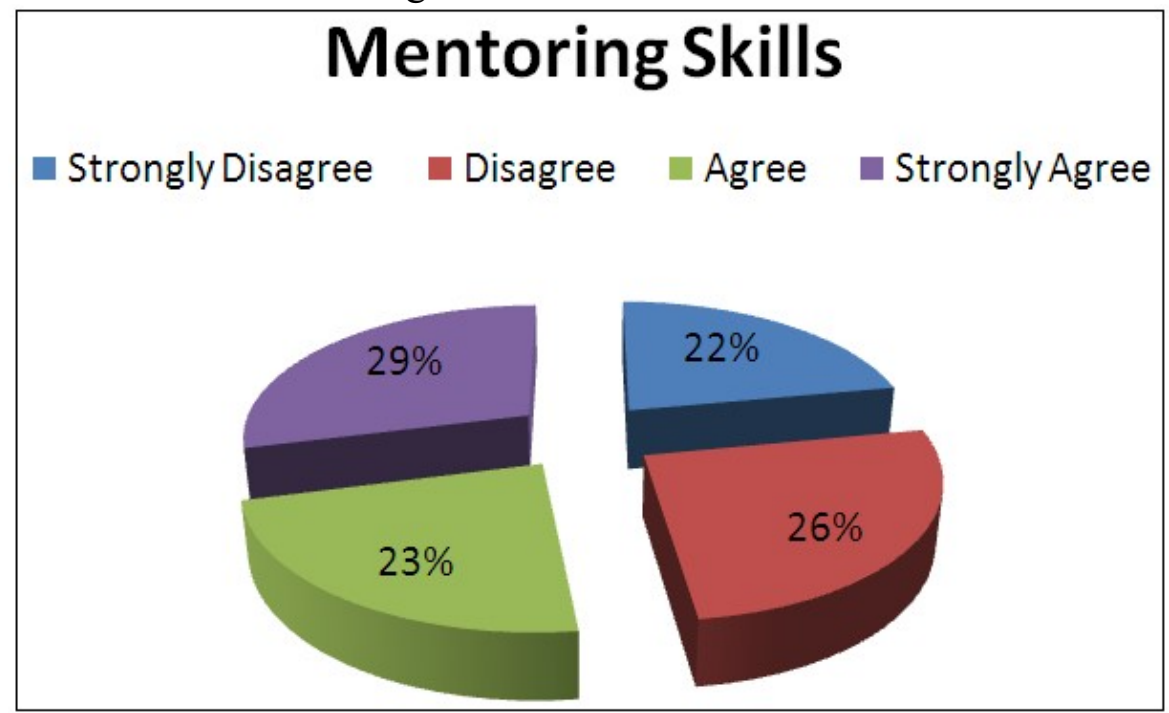

Table 6 provides the data showing these different aspects of the Mentoring Skills of corporate leadership. It is found that overall 246 per cent of the participants did not agree and 254 per cent agreed. Out of 246 per cent of not agreed the highest per cent denied i.e. 57 per cent in the aspects of a leader shares tales of his / her own success and failures when he/she thinks examples are needed. And out of overall 254 per cent of agreed respondents 58 per cent are agreed in the aspects of a leader listen alternatively to both words and feelings of his / her protégé.

Table 6: Comprehensive Mentoring Skills

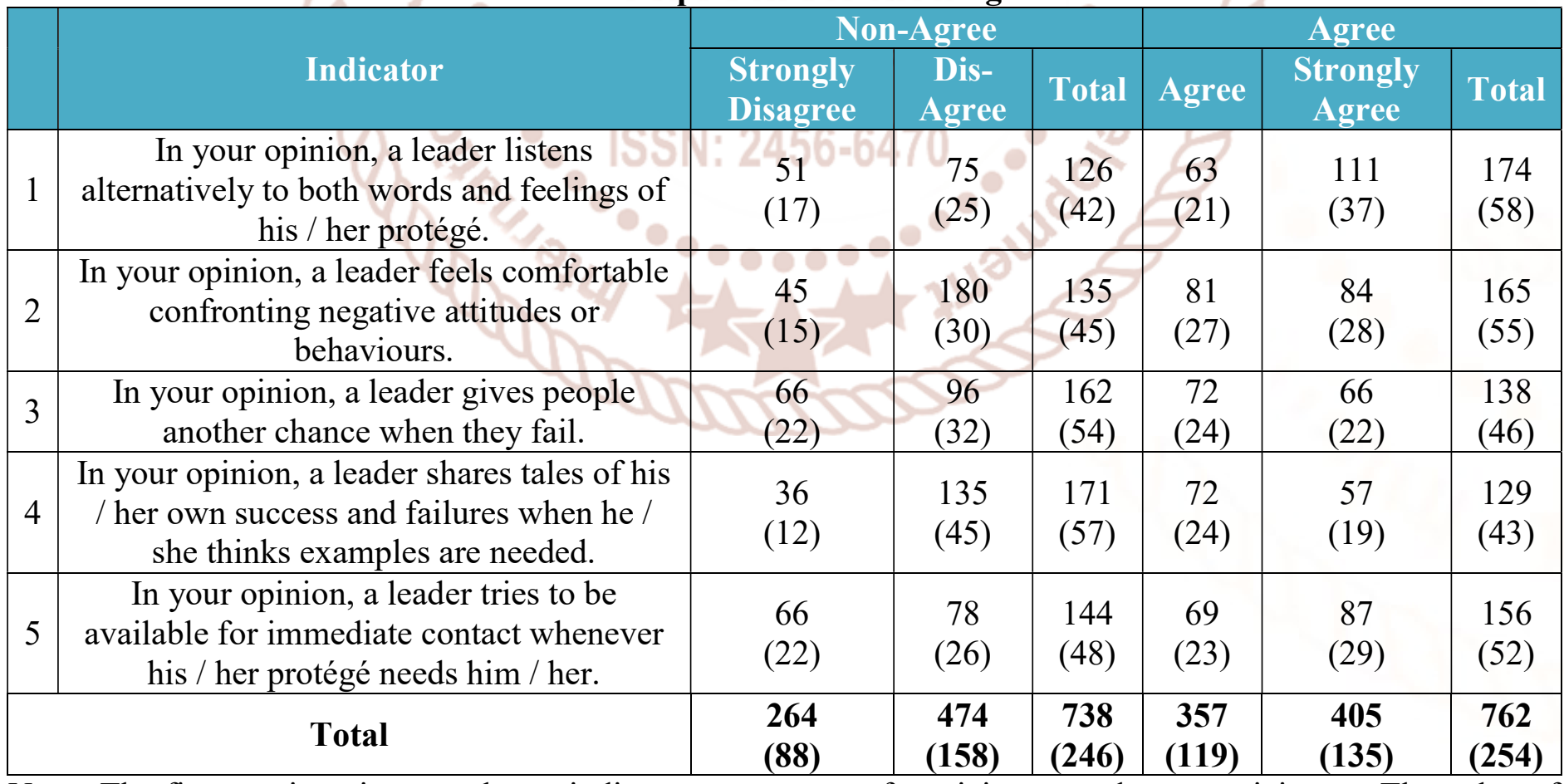

Note: The figures given in parentheses indicate percentages of participants and non-participants. The value of Chi-square $(\chi 2)$ is 6.13 between participants with disagree and agree. The table values at 5 per cent with 4 degree of freedom are 9.48 . 
Figure 7: Comprehensive Mentoring Skills

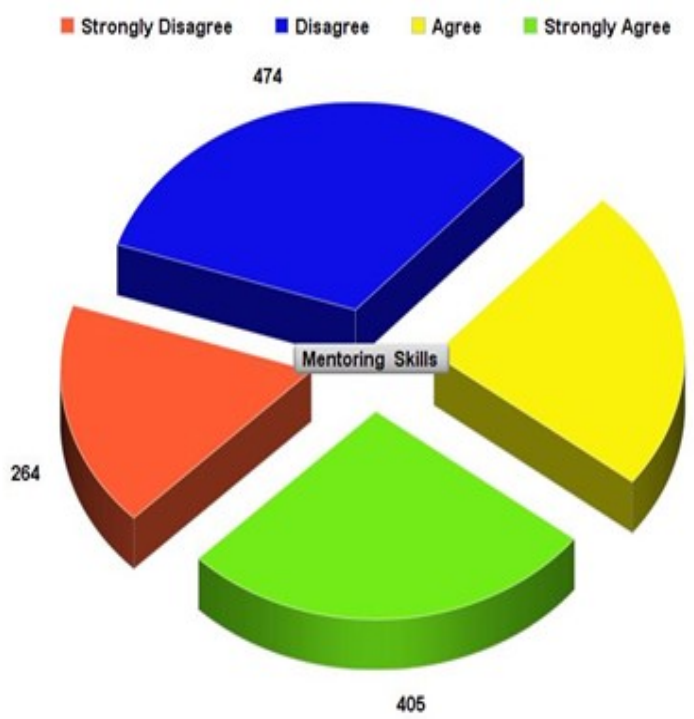

405

A comparative analysis is made to know the impact of Mentoring Skills, in between agreed participants with the non-agreed participants consisting of different relevant indicators of Mentoring Skills. The significance of the difference between agreed participants with the non-agreed participants consisting of different relevant indicators of Mentoring Skills is measured with Chi-square $(\chi 2)$ test. Here, the table value of Chi-square $\left(\chi^{2}\right)$ for 4 degrees of freedom at $5 \%$ level of significance is 9.48 whereas the result of $\left(\chi^{2}\right)$ test found the critically value 6.13 which is less than this value. So, there is a significant impact of Mentoring on corporate leadership.

\section{CONCLUSION}

Mentoring seems to be the right answer at the right time for corporate to protect their corporate knowledge, change their corporate cultures in order to attract and retain a younger and diverse employee base, enhance innovation and creativity and lower costs. The question to ask is whether corporate are talking full advantages of the opportunity mentoring appears to offer. This research article has offered a more holistic look at the mentoring landscape from a global perspective. The findings of this research article both validate previous research and point to new areas of research that will prove valuable to practitioners and those working to design $21^{\text {st }}$ century mentoring, leading and learning solutions for the workplace.

The theoretical propositions that emerged from this research began with seeing that in the workplace, mentoring can be understood as a triad relationship

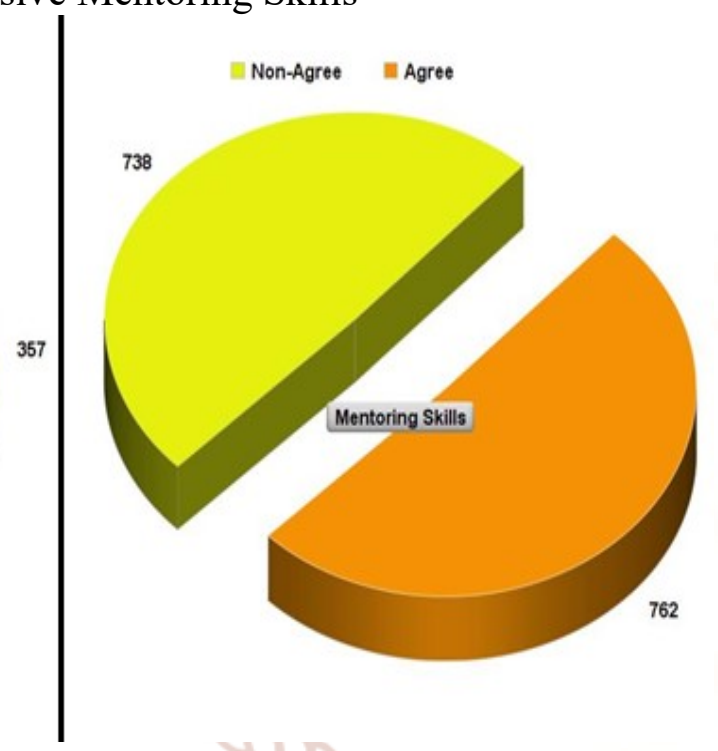

composed of a mentor, mentee and corporate leader, with each one perceiving this shared experience both similarly and differently. This is a perspective that has little voice in the mentoring literature. A betterunderstood perspective is that in the workplace, the corporate culture has a pervasive influence on the experience of mentoring for participants in the mentoring relationship. Understanding the corporate leader as being instrumental in the work culture is accepted doctrine and yet the potential instrumentality of the leader's role in the mentoring experience of their employees is not addressed in the mentoring literature, although it does receive significant attention in the supervisory counselling literature.

The acknowledgement that learning is embedded in the corporate culture is well documented in the literature on adult learning theory. However, the interactive effect between the mentor as a learning leader, the mentee as a reciprocating learner, the manager as a corporate leader and the culture as a learning corporate and the resultant interrelationship between learning, leadership and mentoring, is not well understood or documented. An understanding of how the diversity of mentoring relationships available in the workplace serves the learning enterprise is not well documented. Although an understanding of the interactive effect between learning, leadership and mentoring and those who perform the interactions is clearly vital to enhancing the whole of the business enterprise, few studies pull these together and fewer still situate them in a cultural context.

This research article brought together these previously fragmented parts so that they could be seen as a whole 
system, operating within the context of the workplace. This synthesis allowed us to conceptualise their interoperation and theorise about how they currently perform while opening a window onto the possibilities of how the components might be arranged to increased advantage.

\section{REFERENCES}

1. Anderson, V., 2004. Research Methods in Human Resource Management. London: CIPD.

2. Baddorf, W. D., Ph.D., 2009. Making meaning of decisions and multiple agency roles in complex moral dilemmas among experienced pastoral mentors: A phenomenal graphic study. Doctoral Dissertation, Fielding Graduate University. (UMI No. AAT 3376884)

3. Bandura, A., 1994. Self-efficacy. In V.S. Ramachaudran (Ed.), Encyclopaedia of Human Behaviour, 4, 71-81, New York, Academic Press. (Reprinted in H. Friedman (Ed.), Encyclopaedia of Mental Health, San Diego, Academic Press, 1988.

4. Bandura, A., 2007. Much ado over a faulty conception of perceived self-efficacy grounded in faulty experimentation. Journal of Social and Clinical Psychology, 26, 641-658.

5. Blass, F. R., \& Ferris, G. R., 2007. Leader reputation: The role of mentoring, political skill, contextual learning, and adaptation. Human Resource Management, 46, 5-19.

6. Bryman, A. \& Bell, E., 2007. The process of quantitative research Business research methods $\left(2^{\text {nd }} E d\right.$.). Oxford: University Press.

7. Castro, S. L., Scandura, T. A., \& Williams, E. A., 2005. The validity of Scandura and Ragins' (1993) multidimensional mentoring measure: An evaluation and refinement. Paper presented at the meeting of the Southern Management Association, San Antonio, TX.

8. Chao, G. T., Walz, P. M., \& Gardner, P. D. (1992), Formal and informal mentorships: A comparison of mentoring functions and contrast with nonmentored counterparts. Personnel Psychology, 45(3), 619-36.

9. Chemers, M. M., Watson, C. B., \& May, T. S., 2000. Dispositional affects and leadership effectiveness: A comparison of self-esteem, optimism and efficacy. Personality and Social Psychology Bulletin, 26, 267-277.
10. Clutterbuck, D., \& Megginson, D. (1999). Mentoring executives and directors. Woburn, MA: Butterworth-Heinemann.

11. Collis, J \& Hussey, R., 2003. Business Research. New York, Palgrave MacMillan.

12. Creswell, J. W., 2014. Research Methods, $\left(^{\text {th }}\right.$ Ed.). Thousand Oaks, CA: Sage.

13. Eby, L. T. (1997). Alternative forms of mentoring in changing organizational environments: A conceptual extension of the mentoring literature. Journal of Vocational Behavior, 51(1), 125-144.

14. Gist, M., 1987. Self-efficacy: Implications for organizational behaviour and human resource management. Academy of Management Review, $12,472-485$

15. Hansman, C.A., 2003. Reluctant mentors and resistant protégés: Welcome to the "real" world of mentoring. Adult Learning, 14(1), 14-16.

16. Hicks, R, \& McCracken, J., 2009. Mentoring vs. coaching-Do you know the difference? Physician Executive, 35(4), 71-74.

17. Holloway, E. L., \& Shoop, M. (2006, June 15). Seeding leaders in place: Mentoring for transformational change. Plenary address, Oxford Mentoring and Coaching Institute Conference, England.

18. Horton, S. S., 1996. Mentor functions on a college campus: Perceptions of students of colour. Doctoral Dissertation, Boston College. (UMNI No. AAT 9713067).

19. Karkoulian, S., Halawi, L. A., \& McCarthy, R. V., 2008. Knowledge management formal and informal mentoring; An empirical investigation in Lebanese banks. The Learning Organization, 15(5), 409-429.

20. Kram, K. E. (1983). Phases of the mentoring relationship. Academy of Management Journal, 26(4), 608-625.

21. Kram, K. E. (1988). Mentoring at work: Developmental relationships in organizational life. Glenview, IL: Scott Foresman.

22. Lankau, M. J., \& Scandura, T. A., 2002. An investigation of personal learning in mentoring relationships: Content, antecedents, and consequences. The Academy of Management Journal, 45, 779-790. 
23. Leedy, P. D., \& Ormrod, J. E., 2005. Practical Research. Upper Saddle River, NJ: Pearson Prentice Hall.

24. Lim, V., 2008. Money and mentorship. Diverse Issues in Higher Education, 25(18), 18- 20.

25. McDaniel, C. \& Gates, R., 2002. Marketing research: the impact of the Internet. Hoboken, $\mathrm{NJ}$ : Wiley.

26. Mezias, J. M., \& Scandura, T. A., 2005. A NeedsDriven Approach to Expatriate Adjustment and Career Development: A multiple mentoring perspectives. Journal of International Business Studies, 36(5), 519-538.

27. Paglis, L. L., \& Green, S. G., 2002. Leadership self-efficacy and managers 'motivation for leading change. Journal of Organizational Behaviour, 23, 215-235.

28. Pajares, F., 1994. Current directions in selfefficacy research. In M. Maehr \& P.R. Pintrich (Eds.), Advances in Motivation and Achievement, 1-49, Greenwich, CT: JAI Press.

29. Raabe, B., \& Beehr, T. A. (2003). Formal mentoring versus supervisor and coworker relationships: Differences in perceptions and impact. Journal of Organizational Behavior, 24, 271-293.

30. Ragins, B. R. (1997). Diversified mentoring relationships in organizations. Academy of Management Review, 22: 482-521.

31. Robson, C., 2002. Real World Research: A resource for social scientists and practitionerresearchers (2 ${ }^{\text {nd }}$ Ed.). Oxford, UK: Wiley Blackwell.

32. Russell, J. E. A. \& Adams, D. M. (1997). The changing nature of mentoring in organizations: An introduction to the special issue on mentoring in organizations. Journal of Vocational Behavior, 51, $1-14$.
33. Saunders, M., Lewis, P. \& Thornhill, A., 2009. Research Methods for Business Students ( $5^{\text {th }} \mathrm{Ed}$.), London, U.K: Financial Times Prentice Hall.

34. Scandura, T. A., 1992. Mentorship and career mobility: An empirical investigation. Journal of Organizational Behaviour, 13, 169-174.

35. Semadar, A., Robins, G., \& Ferris, G. R., 2006. Comparing the validity of multiple social effectiveness constructs in the prediction of managerial job performance. Journal of Organizational Behaviour, 27, 443-461.

36. Stead, V. (2005). Mentoring: a model for leadership development? International Journal of Training and Development, 9(3), 170-84.

37. Tannenbaum, S. I. (1997). Enhancing continuous learning: Diagnostic findings from multiple companies. Human Resource Management, 36, 437-452.

38. Wagner, C. G., 2009. When mentors and mentees switch roles. The Futurist, 43(1), 6-8.

39. Walker, K. M., 2008. Women leading men: A look into the phenomenon of leadership from the perspective of women officers in the military. Doctoral Dissertation, Capella University. (UMI No. AAT 3307912).

40. Wallin, D. C., \& Crippen, C., 2008. Mentorship and gendered assumptions: Examining the discourse of Manitoba superintendents. EAF Journal, 19(2), 56-76.

41. Wilson, J. A., \& Elman, N. S. (1990). Organizational benefits of mentoring. Academy of Management Review, 4, 88-93.

42. Zachary, L.J. (2005). Creating a mentoring culture: The organization's guide. San Francisco, CA: Jossey-Bass. 